MUSICA THEORICA 201600

EDITORIAL

Data de finalização: 20/07/2016

\title{
Editorial 1(1)
}

\section{Rodolfo Coelho de Souza}

Universidade de São Paulo

rcoelho@usp.br

Editor-chefe de MUSICA THEORICA

Há cerca de dois anos lançou-se a ideia de fundar uma Associação Brasileira de Teoria e Análise Musical, a TeMA. Um objetivo correlato imediatamente aventado foi que ela abrigasse a criação de uma revista acadêmica que acolhesse e aumentasse a visibilidade da produção intelectual de nosso meio acadêmico na sua área de conhecimento musical. Este projeto concretiza-se agora com o lançamento do primeiro volume da revista MUSICA THEORICA.

Naquele momento não havia como mensurar se a iniciativa era prematura ou oportuna. Na área de música, prevalece no Brasil o modelo de revistas acadêmicas atreladas aos programas de pós-graduação, conforme as normativas da Capes. De acordo com esse modelo, as revistas acadêmicas devem aceitar publicações de todas as linhas de pesquisa do programa de pós-graduação ao qual estão vinculadas. Resulta disso que a maior parte de nossas revistas tem um perfil generalista, abrigando artigos de muitas especialidades, tais como musicologia histórica, etnomusicologia, educação musical, composição, performance, sonologia, cognição musical, percepção, teoria e análise, etc, apenas para mencionar algumas alternativas de uma extensa lista.

Temiam alguns colegas que a proposição de uma revista especializada em Teoria e Análise Musical, sem vínculos com algum programa de pós-graduação, mas ligada a uma associação de área, se revelasse uma proposição precipitada. Não era clara, para nossa comunidade, a existência de uma massa crítica de pesquisa e produção de artigos, em quantidade suficiente para sustentar a rotina editorial de um periódico acadêmico especializado. O lançamento deste primeiro volume dirime essa dúvida, demonstrando que a produção brasileira desta área é abundante, consistente e original. 
Por outro lado, o cenário internacional também indicava que a especialização dos periódicos era o melhor caminho a seguir, ainda que fosse necessário atravessar um estágio inicial em que a produção se mostrasse tíbia. Nos países mais avançados as revistas acadêmicas de maior impacto estão vinculadas a associações similares à TeMA, ou são parte de um complexo editorial universitário ou empresarial, todavia sempre temáticas, ou seja, especializadas em uma área de conhecimento. Como exemplos deste modelo na área de Teoria e Análise Musical podemos mencionar os seguintes periódicos: Journal of Music Theory, Music Theory Spectrum, Music Theory Online, Dutch Journal of Music Theory, Music Analysis, Musik Theorie, entre diversos outros.

Como motivação adicional para o lançamento de MUSICA THEORICA havia a dificuldade que os pesquisadores brasileiros encontram para publicar em revistas internacionais. São diversos os obstáculos a serem vencidos, além da questão de escrever em língua inglesa, que hoje parece o menor deles. Ao meu ver, o maior obstáculo está ligado ao desinteresse daquelas revistas pelos objetos de estudo que interessam aos pesquisadores brasileiros, especialmente quando os estudos analíticos se debruçam sobre a música brasileira, latino-americana ou ibero-americana. Nos artigos desta primeira edição de MUSICA THEORICA o leitor encontrará análises de obras de Ernst Widmer, Paulo Costa Lima, Paulo Rios Filho, Camargo Guarnieri, Elis Regina, Caetano Veloso, Heitor Villa-Lobos, César Guerra-Peixe, Eunice Catunda, Claudio Santoro, Esther Scliar e Edino Krieger, o que não se imagina que pudesse acontecer em algum dos periódicos internacionais acima mencionados. Além disso, a dificuldade não é menor quando um pesquisador brasileiro se aventura no repertório dos compositores do cânone internacional. Sabemos nós que, por exemplo, as contribuições de pesquisadores brasileiros aos estudos sobre Olivier Messiaen e Paul Hindemith - apenas para mencionar dois autores que figuram nos artigos deste volume concorreriam em condições desiguais com a acirrada competição de submissões das revistas internacionais. No ambiente editorial de MUSICA THEORICA essa produção encontra seu espaço e sua originalidade é reconhecida pelos pares.

Pelos motivos expostos acima, a revista Musica Theorica propõe-se a criar uma plataforma de divulgação de pesquisas originais na área de teoria e análise, independente da centralidade canônica dos objetos de estudos e da origem dos pesquisadores, incentivando a submissão de artigos em inglês para que os artigos obtenham boa visibilidade internacional numa publicação online que adere ao princípio do open access.

Registramos, ainda uma vez, que se demonstrou infundado o receio de que o volume de produção na área e de submissão de artigos à revista $\mathrm{Musica}$ Theorica tivesse um fluxo insuficiente para sustentar sua periodicidade. O projeto foi acolhido com grande entusiasmo pela comunidade de pesquisadores 
brasileiros que patrocinou seu lançamento. Em pouco tempo a revista recebeu uma quantidade significativa de textos, antes mesmo que se pudesse lançar uma chamada pública. A notícia do lançamento da Revista nos congressos e encontros promovidos para a constituição da TeMA foi suficiente para provocar uma forte adesão de associados ao projeto da publicação. Constatou-se assim a existência de uma quantidade, talvez até inesperada, de pesquisadores brasileiros dedicados à área de teoria e análise musical. Selecionamos para o primeiro número da revista uma amostra de artigos que testemunha o variado panorama de pesquisas em curso no Brasil e no qual despontam como autores diversos membros da TeMA.

Abrindo o primeiro volume registramos o privilégio de receber para publicação um artigo do eminente musicólogo norte-americano Elliott Antokoletz, parte de sua monumental pesquisa sobre a obra de Béla Bartók. Esse artigo contribui significativamente para ampliar o perfil internacional do lançamento de MUSICA THEORICA. Em seu artigo Antokoletz celebra a função proeminente que as disciplinas de teoria e análise desempenham em suas pesquisas musicológicas. Nesse intuito ele demonstra como as proposições de George Perle desempenharam um papel seminal na teorização de um sistema tonal não-tradicional baseado em ciclos intervalares e simetria inversional, teoria esta que Antokoletz utiliza para analisar a música de Bartók. O autor comenta ainda algumas análises de Bartók por alguns de seus predecessores para defender a efetividade da aplicação de seu modelo analítico.

Comentamos acima que os textos publicados no volume de lançamento de MUSICA THEORICA revelam a ampla diversidade de métodos, abordagens e objetos de interesse presentes no cenário da pesquisa em teoria e análise no Brasil. Veremos que fundamentos de filosofia e estética são utilizados por alguns autores para orientar suas pesquisas, enquanto outros optam por modelos matemáticos ou geométricos e computacionais. As correntes de análise estrutural da linguagem comparecem com muito vigor, assim como abordagens da significação musical que tratam de problemas de expressividade musical e de intertextualidade.

O artigo de Ilza Nogueira apropria-se de conceitos da filosofia da música propostos por Gilles Deleuze, Félix Guatarri e Sílvio Gallo para analisar a evolução do pensamento composicional de compositores da Bahia entre os anos de 1980 a 2010, dentre os quais se destacam Ernst Widmer, Paulo Costa Lima e Paulo Rios Filho. A elegante análise de obras desses autores proposta pela autora desvenda o fascinante diálogo entre o local e o universal que está presente na produção desse grupo de compositores.

Perseverando em sua linha de pesquisa de processos computacionais aplicados à música, Carlos de Lemos Almada estuda o problema da variação 
musical, propondo duas estratégias de produção sistemática e de controle populacional de formas variantes de uma célula musical básica. Inspirando-se em modelos da Biologia, essas estratégias são baseadas nos princípios de seleção artificial e adaptação propostos pela Teoria da Evolução de Charles Darwin.

Uma aproximação entre conceitos da Matemática e da Música é proposta pelo artigo de Luciana Gastaldi S. Souza, Tadeu Moraes Taffarello e Naresh Kumar Sharma que estuda o problema das permutações simétricas na obra de Olivier Messiaen. Abordando a técnica das permutações de Messiaen pela ótica da geometria, os pesquisadores procuram esclarecer em que sentido essas operações são de fato simétricas e a seguir buscam sua aplicação analítica à técnica de tratamento do ritmo na obra do compositor francês.

Situado no campo das análises estruturais, o artigo de Antenor Ferreira Corrêa reconhece como os procedimentos de centralidade pós-tonal, tonalidade suspensa e parcimônia colaboram para operar uma desconstrução do discurso tonal na linguagem musical de Camargo Guarnieri. Com base nesses princípios, o autor propõe um método analítico de estudo da linguagem composicional dos Ponteios de Camargo Guarnieri. Abre-se assim um campo fértil para o estudo da obra de um dos principais compositores brasileiros cuja recepção internacional pode crescer com as contribuições da nossa musicologia analítica.

Abrindo espaço num campo ainda pouco desbravado pela pesquisa acadêmica, nacional e internacional, Fausto Borém apresenta, em um artigo de substancial originalidade, a utilização de duas ferramentas analíticas, o MaPA (Mapa de Performance Audiovisual) e a EdiPA (Edição de Performance Audiovisual), com as quais ele propõe um método de estudo dos conteúdos de gravações de vídeo de música. Aplicando essa metodologia a gravações áudiovisuais de Elis Regina e Caetano Veloso, e levando em consideração a interferência da direção artística, o autor reconhece os níveis de liberdade e de planejamento na realização desses produtos, considerados paradigmáticos na área de vídeo-música do Brasil.

Entre os problemas da significação musical cuja complexidade ainda resiste a abordagens conclusivas, considera-se a questão da expressividade musical como um desafio em aberto. Luciano de Freitas Camargo e Paulo de Tarso Salles enfrentam esse problema utilizando uma versão contemporânea da vetusta teoria dos quatro temperamentos, que remonta a uma proposição de Hipócrates na Antiguidade grega. A partir desse esquema conceitual elaboram uma proposta analítica da expressão musical da obra Thema mit vier Variationen "Die vier Temperamente" de Paul Hindemith, onde o compositor realiza quatro variações sobre um tema que representam, respectivamente, os quatro temperamentos hipocráticos: sanguíneo, fleumático, melancólico e colérico. 
Contribuindo com mais um trabalho neste volume, Paulo de Tarso Salles apresenta um estudo sobre a questão da distância tonal, a partir de pressupostos de Lewin, Cohn e Tymoczko, entre outros. O autor demonstra como os ciclos octatônicos formados por acordes de sétima podem se conectar com as tríades consonantes dos ciclos hexatônicos descritos por Cohn. A conexão entre acordes de diferentes cardinalidades é feita com a ajuda de uma região harmônica denominada "região Euler", na qual uma topologia de tríades aumentadas resulta em acordes maiores com sétima maior. A seguir, o autor aplica sua proposição teórica na análise de fragmentos de um quarteto de Villa-Lobos para ilustrar a importância das regiões Euler entre as tétrades e tríades perfeitas.

Ainda no vasto campo da significação musical, utilizando especificamente as teorias da intertextualidade e da narratividade, contextualizadas no ambiente histórico e social da época, Cristina Capparelli Gerling discute como os princípios formais do neoclassicismo contribuíram para a composição de oito sonatas para piano brasileiras, escritas pelos integrantes do Grupo Música Viva (Guerra-Peixe, Catunda, Santoro, Scliar e Krieger) entre 1950 e 1967. O principal argumento da autora é o reconhecimento de características compartilhadas, proeminentes nas oito peças, e em especial ao papel do uníssono no complexo temático inicial de cada sonata, seguidos da apresentação de tipos dramáticos de caráter heroico e cômico. 